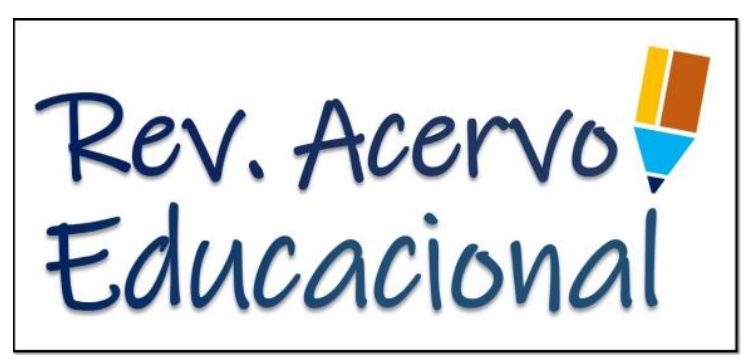

\begin{tabular}{c} 
REVISÃO BIBLIOGRÁFICA \\
\hline Recebido em: 10/2019 \\
Aceito em: 11/2019 \\
Publicado em: $2 / 2020$ \\
\hline
\end{tabular}

\title{
Considerações sobre o brincar: porque os brinquedos auxiliam e podem influenciar nos processos de aprendizado
}

\author{
Play considerations: why toys help and can influence learning processes
}
Consideraciones sobre el juego: porque los juguetes ayudan y pueden influir en los procesos de aprendizaje

\section{Adriano Junio Moreira de Souza ${ }^{1 *}$}

\begin{abstract}
Resumo: Este artigo teve como objetivo discutir a importância do brincar nos processos de aprendizagem. O brincar acompanha a humanidade desde os tempos antigos, funcionando como uma forma de interface que permite à criança acessar aspectos do mundo adulto em seu próprio espaço existencial. Nesse viés, o brincar foi abordado como um comportamento evolutivamente conservado, apresentando um caráter universal em um cronograma definido. Concluiu-se que inicialmente a brincadeira pode auxiliar no processo de desenvolvimento sensorial e motor, em um segundo momento, através do "faz de conta", as crianças podem simular o mundo real, extraindo dessa simulação a experiência necessária para aprender o máximo de nuances do comportamento, como os fundamentos da socialização e da comunicação humana.
\end{abstract}

Palavras-chave: Infância, Cultura, Neurobiologia.

Abstract: This article aims to discuss the importance of playing in learning processes. Playing has accompanied humanity since ancient times, functioning as a form of interface that allows children to access aspects of the adult world in their own existential space. In this bias, playing was approached as an evolutionarily conserved behavior, presenting universal character in a defined schedule. It was concluded that, initially, play can assist in the process of sensory and motor development, in a second moment, through "make believe", the children can simulate the real world, extracting from this simulation the experience necessary to learn as much as possible. nuances of behavior, such as the foundations of socialization and human communication.

Keywords: Childhood, Culture, Neurobiology.

Resumen: Este artículo tiene como objetivo discutir la importancia de jugar en los procesos de aprendizaje. Jugar ha acompañado a la humanidad desde la antigüedad, funcionando como una forma de interfaz que permite a los niños acceder a aspectos del mundo adulto en su propio espacio existencial. En este sesgo, el juego fue abordado como un comportamiento conservado evolutivamente, presentando el carácter universal en un horario definido. Se concluyó que, inicialmente, el juego puede ayudar en el proceso del desarrollo

${ }_{1}^{1}$ Centro Universitário Tocantinense Presidente Antônio Carlos - UNITPAC; Faculdade Católica Dom Orione

- FACDO. Araguaína - TO. *E-mail: junio.adriano@hotmail.com 
sensorial y motor, en un segundo momento, a través de "hacer creer", los niños pueden simular el mundo real, extrayendo de esta simulación la experiencia necesaria para aprender más. matices de comportamiento, como los fundamentos de la socialización y la comunicación humana.

Palabras clave: Infancia, Cultura, Neurobiología.

\section{INTRODUÇÃO}

O brincar é fundamental para o desenvolvimento saudável das crianças oferecendo benefícios físicos, emocionais, cognitivos e sociais. Permite que as crianças desenvolvam habilidades motoras, experimentem seu repertório social e comportamental, simulem realidades alternativas e elaborem as várias consequências positivas e negativas de seu comportamento em um contexto seguro e amigável. $O$ brincar parece ser um comportamento conservado evolutivamente porque apresenta um caráter universal e aparece em um cronograma definido (BURGHARDT GM, 2005; SMITH P, 2009). Dessa forma, a luta fingida apresentada pelos animais pode servir como um análogo ao brincar nos humanos, já que ambas as atividades envolvem simbolismo, sinalização metacomunicativa e regulação emocional. As funções adaptativas do brincar incluem auxílio ao comportamento social e regulação emocional (OLIVEIRA S, et al., 2003). Evidências apontam que o jogo de fingimento - brincadeira - pode servir a funções semelhantes para os animais - humanos e não humanos (BURGHARDT GM, 2005). Inicialmente o brincar auxilia no desenvolvimento sensorial e motor, em um segundo momento, através do "faz de conta", as crianças - e os filhotes - simulam o mundo real, extraindo desse "fingimento" a experiência necessária ao aprendizado das mais diversas nuances do comportamento, como os fundamentos da socialização e comunicação. Neste viés, os brinquedos já foram referidos por sua importância em relação ao brincar (BENJAMIN W, 1984).

Apesar de os brinquedos - através do brincar - desempenharem um papel fundamental em processos desenvolvimentais e da socialização, o registro da história dos brinquedos foi referido por ter tido início tardio (BURTON A, 1997). Segundo Burton A (1997), só em meados do século XIX se passou conservar a história dos brinquedos - mais precisamente - a virada do século XIX para o século XX foi mencionada por um balanço histórico dos brinquedos produzidos até aquele momento. Esse balanço retrospectivo dos brinquedos foi documentado por Henry Rene d'Allemagne (1863-1950) (BURTON A, 1997). Para Burton A (1997) foi este o momento no qual a história dos brinquedos teve início (BURTON A, 1997).

Com base nestas observações, o objetivo desse trabalho foi realizar uma revisão sobre a importância dos brinquedos para os processos de aprendizado e socialização. Será discutido brevemente como o ato de brincar está presente na história da humanidade desde tempos antigos funcionando como uma interface que permite que a criança acesse aspectos do mundo dos adultos em seu próprio espaço existencial. Também será abordado o impacto das questões culturais sobre os brinquedos e como isso pode impactar o brincar, que demonstra ser uma tendência natural e historicamente relacionada ao aprendizado.

\section{REVISÃO DE LITERATURA}

\section{Do brincar ao brinquedo e suas funções}

O brincar "se tornou" um mediador que prepara para a vida social (MEIRA AM, 2003). Essa transformação se deu mediante ao desenvolvimento da cultura e acompanha suas transformações (BENJAMIN W, 2002). Portanto, os brinquedos - do passado - não dão indicativos de uma existência independente das questões sociais, apontam sim, a existência de um diálogo entre as crianças e os adultos (BENJAMIN W, 2002).

Diversos tipos de brinquedos são passados de geração em geração, todavia, a maneira de brincar com eles é modificada em decorrência dos costumes e valores de cada época. Como pode ser constatado (BURGHARDT GM, 2005), o que prevalece na filogênese é o mais natural - que é o ato de brincar. E o brincar é parte fundamental da formação e socialização do sujeito (GREENOUGH WT, 1975). 
De fato, já foi discutido por Burghardt GM (2005) que o brincar prevaleceu como um comportamento conservado entre muitas espécies. Não apenas entre os mamíferos, mas também, entre outros animais como as aves e os peixes, que expressam esse comportamento com a mesma finalidade, que é adaptação seguida de socialização. Todavia, é importante considerar que no caso dos humanos - a partir do surgimento da cultura - o brincar passou a ser direcionado - em grade escala - pelo brinquedo. Quanto a isso, é importante considerar que o "faz de conta" para a criança não é um "passatempo", mas é sim, a maneira mais natural e evolutivamente antiga de aprender sobre o mundo, a natureza e sobre sua espécie (LILLARD AS, et al., 2017; YANOF JP, 2013).

Somado a isso, a experiência na interação com o ambiente tem um impacto profundo no desenvolvimento, perpassando por suas diversas dimensões, neurobiológica, comportamental e psicológica (GREENOUGH WT, 1975). O brincar deriva de uma demanda do organismo em desenvolvimento por interação e elaboração de suas experiências e vivências (YANOF JP, 2013). Portanto, essa parece ser a base para a explicação mais elementar do impacto dos brinquedos sobre o aprendizado cultural e 0 enquadramento nas normas sociais.

\section{O brinquedo na civilização}

Os brinquedos retratam aspectos centrais da cultura de cada povo e de cada período na história da civilização (BENJAMIN W, 1984). Questões como a política e a economia, assim como as relações que se estabeleceram entre adultos e crianças- em cada época - estão estritamente ligadas aos brinquedos (MEIRA AM, 2003). Por conseguinte, antes do advento da indústria, a produção de brinquedos, assim como de outros produtos, estava ligada ao trabalho artesanal. Já foi observado que naquele período os brinquedos eram construídos por múltiplos profissionais a partir de materiais diversos (MEIRA AM, 2003).

Isso imprimia um caráter identitário ao brinquedo, relacionado ao local onde era feito, o tipo de material e a técnica de construção (MEIRA AM, 2003). O brinquedo feito por um ferreiro ou o brinquedo feito pelo carpinteiro tinham por sua vez os sinais daquela profissão (MEIRA AM, 2003). O que era uma forma lúdica de as crianças interagirem, conhecerem e aprenderem sobre o trabalho dos seus pais (BENJAMIN W, 1984). Essa relação foi sendo modificada na medida em que os brinquedos se tornaram objeto de produção industrial (MEIRA AM, 2003).

A produção industrial de brinquedos é criticada por destituir o brinquedo de uma identidade própria relacionada a um povo ou nação (MEIRA AM, 2003). O lado negativo é apontado sob o argumento de que a criança que brinca passou a não saber de onde vem aquele brinquedo, ou do que ele é feito - ou como se faz (MEIRA AM, 2003). Os brinquedos industrializados, apesar de serem estruturados e pensados para 0 desenvolvimento de habilidades - e manutenção de costumes - são criticados por serem limitantes.

\section{As questões culturais e o aprendizado pelo brinquedo}

De acordo com Benjamin W (2002), o brinquedo em si não deve definir a brincadeira da criança, mas é a criança, que ao brincar, deve transformar um objeto com o qual interage em brinquedo. Como escreveu Benjamin (1986) "A criança não brinca apenas de ser comerciante ou professor, mas também moinho de vento e trem" (BENJAMIN W, 1984, p.108).

As crianças possuem uma "grande" capacidade de reconhecer a importância de suas experiências e vivências, portanto, buscam elabora-las. E esse é um processo de intenso aprendizado que se dá em grande escala por via do brinquedo (MEIRA AM, 2003). Por conseguinte, os brinquedos que imprimem regras demasiado rígidas para o ato de brincar são descritos por não satisfazem a essa tendência natural.

Segundo alguns autores, a criança ao brincar reconhece e reinventa o mundo com os valores e significados de sua época, um processo dinâmico, resultante de suas experiências mais imediatas e de suas tendências naturais. Como já foi observado, a maioria dos mamíferos nasce preparada para uma existência marcadamente definida, portanto, ousar remodelá-los se mostra uma tarefa bastante improdutiva (HARARI YN, 2015). Ao contrário da maioria dos animais, os humanos nascem com uma imensa capacidade de se adaptar, logo podem ser moldados com extraordinária liberdade (HARARI YN, 2015). 
É por isso que cada cultura - em diferentes épocas - "pôde e pode" educar seus filhos para serem cristãos, muçulmanos, budistas, capitalistas, socialistas, guerreiros ou pacifistas (HARARI YN, 2015). Como já foi observado por Benjamin W (1984), diferentes culturas imprimem nos brinquedos seus mitos, costumes e política, os transmitindo as gerações seguintes pelo brincar. Desse modo, todo brinquedo carrega em si a semente da cultura em que se insere a sua elaboração e produção, a começar pela época, o modo de ver o mundo e de relacionar-se com as crianças. Somado a isso, está a forma de educar e apresentar a tradição (MEIRA AM, 2003). Por assim dizer, uma ideação de sociedade passa pelo brinquedo.

Não obstante, ainda sim, existe algo de natural no ato de brincar (BURGHARDT GM, 2005), é o que aproxima o ser de sua natureza. Talvez se possa ariscar em dizer que o brincar aproxima o humano da natureza e o brinquedo o aproxima da cultura. Ou como notou outro autor, a infância é o estágio em que o ser mais se aproxima de sua natureza (RAJOBAC R, 2011). A infância é um "oceano de potencialidades", por assim dizer, as brincadeiras de faz de conta podem servir para refinar a sensibilidade das crianças aos sinais sociais. Considerando o ponto de vista evolutivo e ontogenético, as "brincadeiras de fingimento" poderiam auxiliar no desenvolvimento da "teoria da mente" (SODIAN B e KRISTEN S, 2010).

Dessa maneira, as "brincadeiras de fingimento" em humanos podem servir a um desígnio análogo ao de "lutar" em outras espécies: em ambos os casos, o brincar pode sensibilizar o organismo para sinais sociais que permitirão a coordenação sofisticada do comportamento social mais tarde na vida (MA L e LILLARD AS 2017). Um bom exemplo disso pode ser observado em relação aos efeitos das diferenças sexuais nas preferências de brinquedos (TODD B, et al., 1986). Essas preferências já foram atribuídas a parâmetros perceptuais provindos de objetos preferidos meninos e meninas (TODD B, et al.,1986). O que segundo os autores pode indicar uma preparação biológica para um papel do sexo masculino ou feminino - que se desenvolverá mais plenamente à medida que preferências perceptuais precoces são atreladas a experiências objetivas mediadas pela socialização.

O cérebro primata gosta de brincar, gosta ainda mais em fases iniciais do desenvolvimento (NIJHOF, V. et al., 2018). Não apenas os primatas, mas outros animais também (BURGHARDT GM, 2005; GINSBURG K, 2007; BELL HC, et al., 2009; LILLARD AS, 2017). O que mostra ser o ato de brincar um comportamento conservado evolutivamente (BURGHARDT 2005, LILLARD AS, 2017). Com base nessa tendência, a espécie humana desenvolveu objetos específicos que motivam, auxiliam e norteiam as brincadeiras (BENJAMIN W, 1984) - é isso o que estamos chamando de brinquedo - todavia, na origem primitiva/natural do ato de brincar existe algo de adaptativo para esse comportamento (LILLARD AS, 2017; MA L e LILLARD AS, 2017). Uma criança na pré-história não brincava de empurrar carinhos, mas, provavelmente brincava reproduzindo o que "via" no cotidiano.

Os brinquedos acompanham as questões culturais (BENJAMIN W, 1984). As crianças brincam com os brinquedos elaborados "dentro" de certos parâmetros culturais e sociais (BURTON A, 1997; BENJAMIN W, 1984). Isso tem um caráter facilitador para a adaptação e reprodução desses mesmos parâmetros quando na vida adulta (MEIRA AM, 2003). Apesar das diferenças, esse fenômeno não está muito distante de uma questão natural, na qual a brincadeira prepara o filhote para o mundo que o espera (BELL HC, et al., 2009). Essa compreensão certamente fortaleceu os laços entre $o$ ato de brincar e as questões pedagógicas. Com o passar do tempo surgiu dessa relação uma série de brinquedos estruturados para as mais distintas funções, desde o aprendizado de ciências até o desenvolvimento de habilidades motoras e sociais (BENJAMIN W, 1984). Advento criticado - em determinados pontos por alguns autores - por limitar o ato de brincar (MEIRA AM, 1984), que é discutido como uma tendência universal e inata ligada ao aprendizado e adaptação (LILLARD AS, 2017; MA L e LILLARD AS, 2017). Por outro lado, estudos comprovaram os efeitos positivos de determinados brinquedos sobre o neurodesenvolvimento e desenvolvimento global das crianças (CORDAZO ST, et al., 2011; NIJHOF V, et al., 2018). Em muitos casos, efeitos terapêuticos são descritos (CHINEKESH K, et al., 2014; YOGMAN G, et al., 2018).

Os brinquedos têm uma história que se interlaça com a história da própria humanidade (BENJAMIN W, 1984). Portanto, suas raízes estão em períodos imemoráveis da trajetória humana e o que os antecede é justamente a tendência para o ato brincar (BURGHARDT GM, 2005). 
Pelo que tudo indica, o manejo dessa tendência pode trazer efeitos benéficos para 0 neurodesenvolvimento, adaptação e aprendizado (CORDAZO ST, et al., 2011). Porém, determinados brinquedos - ou o modo de sua utilização - podem influenciar negativamente o neurodesenvolvimento. Os jogos de videogame já foram descritos por afetar regiões do cérebro responsáveis pela recompensa e controle de impulsos - como córtex pré-frontal. A literatura adverte que vias dopaminérgicas do sistema de recompensa - geralmente associadas com dependência de substâncias - estão implicadas com o uso constante de videogames. No entanto, a pesquisa nesse campo já foi referida por ser insuficiente para comparar a "dependência de jogos" com a dependência de substâncias (WEINSTEIN A e LEJOYEUX M, 2015).

Por outro lado, em jogadores de videogame, já foram encontradas diferenças significativas em regiões cerebrais relacionadas com o processamento da tomada de decisão (GOTTSCHALK F, 2019). Em jogadores frequentes foi descrito um maior volume de massa cinzenta em regiões frontais, associado a menor tempo de decisão em comparação com jogadores pouco frequentes (GOTTSCHALK F, 2019). Também já foi observado aumento da conectividade em regiões implicadas em processos como aprendizado procedural na aquisição de novas habilidades através da prática. Outras evidências indicam que pode haver melhora em aspectos da atenção seletiva e habilidades para aprender novas tarefas. Os jogos de videogame também foram correlacionados com uma melhor memória de trabalho e com uma melhor capacidade em habilidades espaciais (GOTTSCHALK F, 2019). De modo geral, os jogos já foram referidos por possibilitar melhoras em habilidades espaciais, e relacionadas ao desempenho em ciências, tecnologia, engenharia e matemática.

\section{O brinquedo como ferramenta pedagógica}

O brincar é parte do processo de ensinar e aprender (BURGHARDT GM, 2005). Quanto a isso, uma pedagogia que amplie as possibilidades de interação entre a criança e o objeto de estudo foi descrita por facilitar o aprendizado (FALKEMBACH G, 2006). Como já foi discutido por outro autor, é brincando que a criança experimenta, inventa, descobre, aprende e confere suas habilidades. Com isso, sua inteligência e sua sensibilidade vão sendo desenvolvidas. Por assim dizer, a educação tem muito a usufruir dessa tendência do organismo a interação através das brincadeiras (BURGHARDT GM, 2005).

Nesse contexto, muitos estudos que empregam brinquedos e brincadeiras pedagógicas descrevem resultados favoráveis para o aprendizado das mais diversas tarefas, desde conteúdos acadêmicos até o aprendizado de determinados comportamentos, como os de interação social (FALKEMBACH G, 2006). Com base nessas evidências é possível afirmar que o brinquedo é um importante mediador entre a tendência da criança - de brincar para aprender - e a demanda do meio - de passar adiante a tradição e o conhecimento, nesse caso, o meio educacional.

\section{O brinquedo como ferramenta terapêutica}

O brinquedo pode direcionar o brincar e o brincar tem efeitos significativos sobre o desenvolvimento do cérebro o que repercute no desenvolvimento da personalidade e no comportamento. A compreensão desses fenômenos se mostrou frutífera para a elaboração de estratégias de intervenção junto a crianças com déficits de aprendizado ou com dificuldades para o desenvolvimento de habilidades sociais. Em muitos casos, os brinquedos têm sido empregados no tratamento de crianças com transtorno do espectro autista (TEA) auxiliando essas crianças no desenvolvimento de habilidades sociais (CONCHINHA C, et al., 2015; LeGOFF D, 2004).

Pesquisadores já observaram que as crianças com TEA apresentam uma clara preferência para se comunicarem com robôs. Foi observado que o robô possibilita um tipo de comunicação mais simples, destituída de ambiguidades e de excesso de sinais. Qualidades que vão ao encontro do que as crianças autistas mais têm dificuldades, que é lidar com a complexidade da comunicação humana (SCASSELLATI B, et al., 2012). O cérebro autista é pouco eficaz em processar a complexidade das interações sociais, o que gera desconforto e leva a dificuldade para o entendimento das nuances sutis da comunicação. No entanto, quando uma criança é estimulada durante a infância a desenvolver determinadas habilidades os resultados 
demonstram ganhos significativos (SCASSELLATI B, et al., 2012). Neste caso, considerar a tendência inerente às crianças para o brincar pode potencializar as intervenções. Não apenas intervenções baseadas no desenvolvimento tecnológico, dentre outras observações, já foi descrito que o jogo de bola - uma das formas mais antigas de brinquedo - pode ser usado como uma técnica de terapia eficaz para facilitar o desenvolvimento da fala em crianças (HUDAK D, 2000). Como já foi referido, o cérebro em desenvolvimento é notadamente responsivo a experiência, o que permite que intervenções precoces possam gerar efeitos consideráveis ao nível do neurodesenvolvimento.

\section{CONSIDERAÇÕES FINAIS}

O aprendizado está ligado ao ato de brincar e - por conseguinte - ao brinquedo, uma relação que vem desde tempos imemoráveis, não apenas da civilização atual, mas, pelo que tudo indica, da espécie. Através do brincar o cérebro pode elaborar o que é experienciado, mimetizar e se preparar para a vida futura. Pelo que tudo indica, foi justamente com base nessa tendência - ou característica - que o brinquedo passou a ser vinculado a um sistema de transmissão de valores culturais. A criança ao receber um determinado brinquedo afeiçoasse/incorpora um determinado escopo. O que está implicado no desenvolvimento de uma diversidade de habilidades. Em síntese, o brinquedo e o brincar tem um impacto sobre o desenvolvimento e o aprendizado, e alterações drásticas no ato de brincar - induzidas por fenômenos culturais - como desenvolvimento tecnológico, tem impactado profundamente o desenvolvimento de crianças. Não apenas ao nível psicológico, mas também neurobiológico e social.

\section{REFERÊNCIAS}

1. BELL HC, et al. The role of the medial prefrontal cortex in the play fighting of rats. Behavioral neuroscience, 2009; 123 (6): 1158.

2. BENJAMIN W. Reflexões: a criança, o brinquedo e a educação. São Paulo: Summus, 1984; 120p.

3. BURGHARDT GM. The genesis of animal play: Testing the limits. Mit Press, 2005; 491p.

4. BURTON A. Design history and the history of toys: Defining a discipline for the Bethnal Green Museum of Childhood. Journal of Design History, 1997; 10 (1): 1-21.

5. CHINEKESH A, et al. The effect of group play therapy on social-emotional skills in pre-school children. Global Journal of Health Science, 2014; 6 (2): 163.

6. CONCHINHA C. et al. La robótica educativa en contexto inclusivo. Ubicuo social: Aprendizage con TIC, 2015.

7. CORDAZO ST, et al., The influence of play in motor, cognitive and social performance in school-age children. Educational Research, 2011; 2 (9):1472-1480.

8. FALKEMBACH GA. O lúdico e os jogos educacionais. CINTED-Centro Interdisciplinar de Novas Tecnologias na Educação, UFRGS, 2006.

9. GINSBURG K. "American Academy of Pediatrics Committee on C, American Academy of Pediatrics Committee on Psychosocial Aspects of $\mathrm{C}$, Family $\mathrm{H}$. The importance of play in promoting healthy child development and maintaining strong parent-child bonds." Pediatrics, 2007; 119(1): 182-191.

10. GOTTSCHALK F. Impacts of technology use on children. 2019.

11. GREENOUGH WT. Experiential Modification of the Developing Brain: The environment and the organism's interactions with it may play an important part in the formation of synapses between nerve cells in the brain. American Scientist, 1975; 63(1): 37-46.

12. HARARI YN. Sapiens: uma breve história da humanidade. Trad. Janaína Marcoantonio. Porto Alegre: L\&PM, 2015; $592 p$.

13. HUDAK D. The therapeutic use of ball play in psychotherapy with children. International Journal of Play Therapy, 2000; $9(1): 1$.

14. LEGOFF DB. Use of LEGO@ as a therapeutic medium for improving social competence. Journal of autism and developmental disorders, 2004; 34(5):557-571

15. LILLARD AS. Why do the children (pretend) play?. Trends in Cognitive Sciences, 2017; 21(11):826-834.

16. MA L, LILLARD AS. The evolutionary significance of pretend play: Two-year-olds' interpretation of behavioral cues. Learning \& behavior, 2017; 45(4):441-448.

17. MEIRA AM. Benjamin, os brinquedos e a infância contemporânea. Psicologia \& sociedade, 2003;15(2):74-87. 
18. NIJHOF SL, et al. Healthy play, better coping: The importance of play for the development of children in health and disease. Neuroscience \& Biobehavioral Reviews, 95, 2018;421-429.

19. OLIVEIRA SS, et al. O lúdico e suas implicações nas estratégias de regulação das emoções em crianças hospitalizadas. Psicologia: reflexão e crítica, 2003; 16(1):1-13.

20. RAJOBAC R. A Importância Do Conceito Rousseauniano De Infância Para A Filosofia Da Educação Musical No Século XXI. Revista Música Hodie, 2011;11(1).

21. SCASSELLATI B, et al. Robots for use in autism research. Annual review of biomedical engineering, 14, 2012; 275294.

22. SMITH PK. Children and play: Understanding children's worlds. John Wiley \& Sons, 2009; 253p.

23. SODIAN B, KRISTEN S. Towards a theory of thinking. Theory of mind, 2010; 189-201.

24. WEINSTEIN A, LEJOYEUX M. New developments on the neurobiological and pharmaco-genetic mechanisms underlying internet and videogame addiction. The American Journal on Addictions, 2015; 24(2):117-125.

25. YANOF JA. Play technique in psychodynamic psychotherapy. Child and Adolescent Psychiatric Clinics, 2013; 22(2):261-282.

26. YOGMAN M, et al. The power of play: A pediatric role in enhancing development in young children. Pediatrics, 2018;142(3): 2018-2058. 